\title{
Design of a survey net for metric survey documen- tation of a historical building
}

\author{
Zdeněk Poloprutský \\ Laboratory of Photogrammetry, Department of Geomatics, Czech Technical University in \\ Prague, Czech Republic \\ zdenek.poloprutsky@fsv.cvut.cz
}

\begin{abstract}
This paper deal with the design and the creation of a survey net during the metric survey documentation of the current state of a historical building. The paper aims to define the general rules for the design of the survey net, which are based on the Least Squares Method (LSM), Huber's M-estimation and the requirement of practical heritage preservation. The paper presents three different examples of survey nets and types of historical buildings.
\end{abstract}

Keywords: adjustment of survey net; detailed survey; GNSS; historical building; Least Squares Method (LSM); metric survey documentation; reference map scale.

\section{Introduction}

The paper deals with the design and the construction of a survey net. A survey net provides the default spatial framework for the metric survey documentation of the current state of a historical building.

Currently, it is already well described by the Least Squares Method (LSM), which is a popular option for calculating the coordinates of survey points in a survey net. For this purpose, LSM is often modified to increase the credibility of their results. Historical buildings are often very complex shape structures, thus, their quality the metric survey documentation requires an individual approach.

This paper tries to formulate general principles for the design and construction of survey nets and for detailed surveys and to summarize the versions of adjustment calculations of a survey net. The outcomes of the paper were tested in three case studies.

\section{General issues}

The metric survey documentation of historical buildings is the essential part of the heritage preservation practice and scientific research into historical architecture taking primarily the form of the Building Archaeological Survey [13]. Good-quality documentation used as the basis for projecting, recognition of projected rebuilding and scientific research, etc. An example of scientific research is e.g. evaluation of the construction development of a particular building, comparison of common features of several buildings, etc. The metric survey documentation of historical building grows into the unique source of information in the case of the destruction of a building or its part - an archival document, a basis for reconstruction, etc.

The submitter of the metric survey documentation has to know the purposes why the metric survey documentation is made and must be aware of the financial means available for it. He must clearly define his requirements and explain them to the contractor. The content of the assignment can be summarized in accordance with the current methodology of the National Heritage Institute - NPÚ [23]: 
1. Precise determination of the subject and the survey area

2. Coordinate system and the vertical coordinate system

3. Required Level of Detail

4. Required Level of Accuracy

5. Required outputs

6. The method of calculating the price and the conditions for its modifications in future

7. Determining the date of submission of the survey

8. Conditions for taking over the finished survey

\subsection{Object and area of surveys}

The survey net has to respect the assignment and connect particular detailed surveys among each other into one whole unit. It is possible to predict the basic dimensions of the survey net and the reference map scale from the area of interest and Level of Detail.

For the design of the survey net, it is useful to use the open data, i.e. base maps, which are freely available on the Internet, such as Geoportal ČÚZK [3], Mapy.cz [19], Open Street Maps [11], etc. The first version of the design of the survey net can be based on them.

It may be useful to prepare field sketches with the design of the survey net for the upcoming detailed surveys. In some cases, it is advisable to print field sketches, see Table 1.

Table 1: Overview of dimensions of survey nets in dependence on reference map scales and paper sizes [12].

\begin{tabular}{|c|c|c|c|c|c|c|}
\hline \multicolumn{2}{|c|}{$\begin{array}{l}\text { Paper sizes }[\mathrm{mm}] \text { by } \\
\text { ISO } 216 \text { / DIN } 476\end{array}$} & \multicolumn{5}{|c|}{$\begin{array}{l}\text { Basic dimensions of survey nets, i.e. width and height, } \\
\text { in dependence on reference map scales }[\mathrm{m}]\end{array}$} \\
\hline$\overline{A A}$ & $\overline{\text { Width } \times \text { Height }}$ & $1: 20$ & $1: 50$ & $1: 100$ & $1: 200$ & $1: 500$ \\
\hline 0 & $841 \times 1189$ & $8 \times 23.8$ & $2.1 \times 59.5$ & $84.1 \times 118.9$ & $168.2 \times 237.8$ & $420.5 \times 594.5$ \\
\hline 1 & 594 & $\times 16.8$ & 29.7 & 4.1 & $118.8 \times 1$ & 297.0 \\
\hline 2 & $420>$ & 1.9 & 21 & 9.4 & 84.0 & $210.0 \times 297.0$ \\
\hline 3 & $297 \times 420$ & 5.9 & 14.9 & 42.0 & 84.0 & $<210.0$ \\
\hline 4 & $210 \times 297$ & $4.2 \times 5.9$ & $10.5 \times 14.9$ & $21.0 \times 29.7$ & $42.0 \times 59.4$ & $105.0 \times 148.5$ \\
\hline
\end{tabular}

\subsection{Selection of geodetic reference systems}

The selection of a geodetic reference system results from the aims of the work, available equipment, base maps and required Level of Detail (LoD) and Level of Accuracy (LoA). Furthermore, the selection of a geodetic reference system often depends on whether the metric documentation will be used in specialized software - CAD, GIS, etc.

Mostly it is easiest to use a local coordinate system. For connect to a geodetic reference system points of horizontal geodetic control and vertical geodetic control must be available, or sufficiently precise equipment for the real-time kinematic (RTK) surveying. 
The Datum of Uniform Trigonometric Cadastral Network (S-JTSK), EPSG: 5514, and the Baltic Vertical Datum - After Adjustment (BpV), EPSG: 5705, are mostly used in the Czech Republic. [17] The selection of national geodetic reference systems enables the supplementation of surveys of the other datasets which are provided by the Czech Office for Surveying, Mapping and Cadastre (Č́́ZK) [17, 3].

\subsection{Choices of levels of detail and accuracy for surveys}

LoD must match the importance of the surveyed building, the purpose for which the given documents are processed, and the resources that are available. Detailed and accurate metric documentation is time consuming and therefore costly. As practice confirms, surveys should always be done to allow the outcomes to be more detailed than the primary documentation. This requirement typically saves a lot of processing time but is not feasible at all times because its limits are related to the choice of survey methods and the cost of labor [23]. It is useful to classify the types of metric documentation into four basic classes:

1. Tentative - mostly sketch, dimensions are estimated, LoD corresponds to a reference map scale of $1: 100$ and below;

2. Basic - usually a metric documentation with side measures, LoD corresponds to a reference map scale of $1: 50$ and below;

3. Detailed - based on a full geodetic measurement, LoD corresponds to a reference map scale of $1: 50$;

4. Shape trustworthy - based on advanced measurement techniques, such as geodetic measurements, laser scanning, photogrammetry etc., LoD corresponds to a reference map scale of $1: 20$.

It is convenient for detailed surveys so that the survey net can be considered faultless. This can be achieved by measuring the survey net with a higher accuracy than the LoA of the required outcomes are. The survey net can be considered faultless in the light of the metric documentation if its standard deviation of distance $\sigma_{d_{i j}}$ does not exceed the limit standard deviation of the distance $\sigma_{T_{d_{i j}}}$, which corresponds to the thickness of the thinnest line of the metric documentation in fact $x_{t l}$.

The horizontal distance $d$ between points $i\left[X_{i}, Y_{i}\right]$ and $j\left[X_{j}, Y_{j}\right]$ is defined as

$$
d_{i j}=\sqrt{\left(X_{j}-X_{i}\right)^{2}+\left(Y_{j}-Y_{i}\right)^{2}} .
$$

The standard deviation of the distance $\sigma_{d_{i j}}$ can be defined in conformity with (1) as

$$
\sigma_{d_{i j}}=\sqrt{\left(-\frac{\Delta X_{i j}}{d_{i j}}\right)^{2} \cdot \sigma_{X_{i}}^{2}+\left(\frac{\Delta X_{i j}}{d_{i j}}\right)^{2} \cdot \sigma_{X_{j}}^{2}+\left(-\frac{\Delta Y_{i j}}{d_{i j}}\right)^{2} \cdot \sigma_{Y_{i}}^{2}+\left(\frac{\Delta Y_{i j}}{d_{i j}}\right)^{2} \cdot \sigma_{Y_{j}}^{2}}
$$

where where simplifications can be defined, such as

- the circle of deviations: $\sigma_{X} \approx \sigma_{Y} \approx \sigma_{X Y}$ and

- the uniform accuracy of the survey net: $\sigma_{X Y_{i}} \approx \sigma_{X Y_{j}} \approx \sigma_{X Y}$. 
After that, $\sigma_{d_{i j}}$ is defined as

$$
\sigma_{d_{i j}}=\sigma_{X Y} \cdot \sqrt{2}
$$

After that, the limit standard deviation of coordinates $\sigma_{T_{X Y}}$ can be deducted in conformity with (2) as

$$
\sigma_{T_{X Y}}=\frac{\sigma_{T_{d_{i j}}}}{\sqrt{2}}=\frac{x_{t l} \cdot M}{\sqrt{2}}
$$

where $M$ is defined as the scale number of the metric documentation. The thickness of a line $x_{t l}$ follows the typographic and cartographic principles that can be taken from the cadastral map [16, 12], see Table 2 .

Table 2: Accuracy analysis of a survey net in dependence on line thicknesses and reference map scales.

\begin{tabular}{|c|c|c|c|c|c|}
\hline Line thicknesses & \multicolumn{6}{|c|}{ Standard deviations $\sigma_{\mathbf{T}_{\mathbf{X Y}}}$ by reference map scales $[\mathbf{m m}]$} \\
\cline { 2 - 6 }$[\mathbf{m m}]$ & $\mathbf{1}: \mathbf{2 0}$ & $\mathbf{1}: \mathbf{5 0}$ & $\mathbf{1}: \mathbf{1 0 0}$ & $\mathbf{1}: \mathbf{2 0 0}$ & $\mathbf{1}: \mathbf{5 0 0}$ \\
\hline \hline 0.13 & 1.8 & 4.6 & 9.2 & 18.4 & 46.0 \\
0.16 & 2.3 & 5.7 & 11.3 & 22.6 & 56.6 \\
0.18 & 2.5 & 6.4 & 12.7 & 25.5 & 63.6 \\
0.20 & 2.8 & 7.1 & 14.1 & 28.3 & 70.7 \\
\hline
\end{tabular}

\section{Mathematical issues}

In the field of geodesy, the metric survey documentation of historical buildings can be classified in a detailed survey, in reference map scales of $1: 20-1: 500$.

The detailed survey is defined as "the observation of objects from points of geodetic point fields, or auxiliary survey points or previously determined detailed survey point" [20].

In the field of geodesy, observations are repeated or other quantities are measured to avoid gross errors and to increase the accuracy of final results. Therefore, the final results are not unambiguous and redundant observations must be adjusted. This approach is most used by the construction of survey nets, which are the necessary geodetic and height basis for detailed surveys.

The Least Squares Method (LSM) has been the most used adjustment method in the field of geodesy since 1806. LSM is the process of adjustment of observed or derived, so-called intermediate, quantities. This process is based on the condition $\Sigma p v v=m i n$., where $p$ are weights of measurements and $v$ are residuals of the observed quantities from the adjustment. LSM is often supplemented by other methods in order to optimize the final results [7].

\subsection{Processing of observations}

In general, observations can be divided into two basic sets:

$l$. . a set of direct measurements of $r$ elements, 
Table 3: Comparison of direct and intermediate measurements in a survey net.

\begin{tabular}{|c|c|c|}
\hline \multicolumn{3}{|c|}{ Direct measurements } \\
\hline$X_{i}, Y_{i}$ & $\left.{ }^{\circ}\right] /[\mathrm{m}]$ & $\begin{array}{c}\text { geocentric coordinates } \\
Z_{i}\end{array}$ \\
\hline$\phi_{i j}$ & {$[\mathrm{gon}]$} & hom GNSS survey \\
\hline$\zeta_{i j}^{\prime}$ & {$[\mathrm{gon}]$} & zenithal distances \\
$d_{i j}^{\prime}$ & {$[\mathrm{m}]$} & slope distances \\
$v_{p}$ & {$[\mathrm{~m}]$} & heights of instruments \\
$v_{c}$ & {$[\mathrm{~m}]$} & heights of targets \\
\hline${ }^{l e v} h_{i j}$ & {$[\mathrm{~m}]$} & levelled height differences \\
\hline
\end{tabular}

\begin{tabular}{|c|c|c|}
\hline \multicolumn{3}{|c|}{ Intermediate measurements } \\
\hline $\begin{array}{c}X_{i}, Y_{i} \\
Z_{i}\end{array}$ & {$[\mathrm{~m}]$} & $\begin{array}{l}\text { geocentric coordinates } \\
\text { from GNSS survey }\end{array}$ \\
\hline$\omega_{i j}$ & [gon] & horizontal angles \\
\hline$\zeta_{i j}$ & [gon] & $\begin{array}{c}\text { reduced zenithal distances } \\
\text { on join of mark stones }\end{array}$ \\
\hline$d_{i j}$ & {$[\mathrm{~m}]$} & $\begin{array}{l}\text { reduced slope distances } \\
\text { on join of mark stones }\end{array}$ \\
\hline$d_{0 i j}$ & {$[\mathrm{~m}]$} & horizontal distances \\
\hline$h_{i j}$ & {$[\mathrm{~m}]$} & $\begin{array}{c}\text { height differences } \\
\text { on join of mark stones }\end{array}$ \\
\hline${ }^{l e v} h_{i j}$ & {$[\mathrm{~m}]$} & levelled height differences \\
\hline
\end{tabular}

$L \ldots$ a set of intermediate measurements of $m$ elements.

The processing of observations consists in the application of math functions between sets $l$ and $L$, i.e. in the calculation of intermediate measurements $m$ from direct measurements $r$, for which the inequality is applied $r \geq m$. The analyses are based on the estimation of the precision characteristics of the math functions between sets $l$ and $L$ and the verification of their values using so-called significance tests of statistical hypotheses. The weights of intermediate measurements $p$ are defined as

$$
P=Q_{L}^{-1}=\left(D \cdot Q_{l} \cdot D^{T}\right)^{-1}
$$

where $P$ represents the weight matrix of intermediate measurements, $Q_{L}$ represents the covariance matrix of intermediate measurements, $Q_{l}$ represents the covariance matrix of direct measurements and $D$ represents the model matrix of the linear relationships between differential changes of intermediate and direct measurements, the so-called matrix of plan.

The math functions for the processing and analyses of intermediate measurements are described in detail in [7].

\subsection{Adjustment of a survey net by the adjustment of redundant observations}

For the adjustment of a survey net it is necessary to have ready a set of intermediate measurements, see Table 3, a set of their standard deviations and a set of approximated coordinates of adjusted points. The unknowns are the coordinates of adjusted points, respectively orientation shifts on adjusted points, in the adjustment calculation. The equation of residual is made for each observation.

The survey net can be aligned asa fixed or loose net. The fixed survey net contains minimally two points of known coordinates, ie. planar or spatial ones, which are part of the net and their coordinates are fixed [7].

The following subsections deal with the adjustment of the fixed survey net in more detail, including modifications considering the inaccuracy of fixed point coordinates, and robust methods for finding remote observations. 


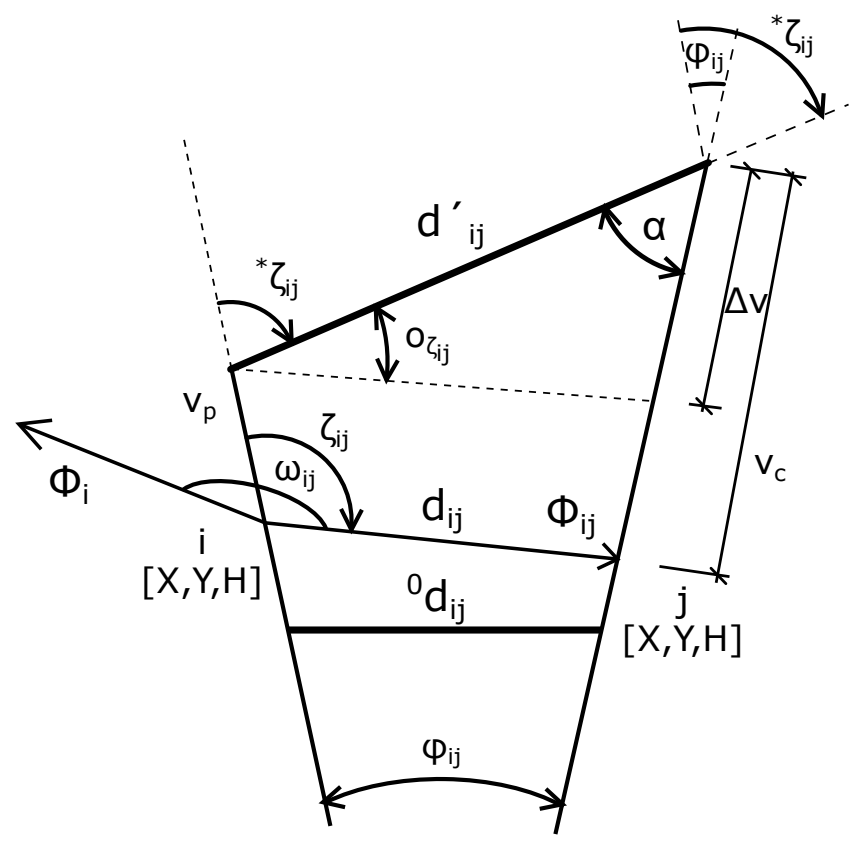

Figure 1: Configuration of direct and intermediate measurements.

Fixed survey net

In general, the adjustment of the fixed survey net by LMS contains three basic sets:

$l$... a set of direct measurements of $r$ elements,

$L$... a set of intermediate measurements of $m$ elements,

$X \ldots$ a set of unknowns of $n$ elements and $p$ conditions.

For the fixed survey net, the configuration condition $p=0$ is defined, i.e.:

$$
r \geq m>n-p \Rightarrow r \geq m>n
$$

The math functions for the adjustment of the fixed survey net by LMS are described in detail in [7]. The summary of the most important of them is presented here:

$$
\begin{gathered}
\hat{v}=A \cdot \hat{d x}+l^{\prime}, \\
\hat{X}=X_{0}+\hat{d x}=X_{0}-\left(A^{T} \cdot P \cdot A\right)^{-1} \cdot A^{T} \cdot P \cdot l^{\prime}
\end{gathered}
$$

and

$$
\hat{L}=L+\hat{v}
$$

where $P$ represents the weight matrix of intermediate measurements $L, A$ represents the matrix of plan intermediate measurements $L$ and $l^{\prime}$ is defined as $l^{\prime}=f\left(X_{0}\right)-L$. 
LMS is defined as an iterative process, i.e. $X_{0}^{j+1}=\hat{X}^{j}$. A condition which completes the iterative calculation with the selected accuracy may be defined as

$$
v^{I} \approx v^{I I}
$$

in that case

$$
v^{I}=A \cdot \hat{d x}+l^{\prime} \approx v^{I I}=f(\hat{X})-L .
$$

Survey net with residuals in bases

In some cases, it may be appropriate to connect the survey net to the points of known coordinates and consider their precision characteristics. By doing this, the aligned coordinates of the network points include not only local accuracy to the connection points but also their global accuracy with respect to the geodetic reference system. The disadvantage of this procedure is the change of the coordinates of the connection, i.e. "fixed", points.

The coordinates of the connecting points are introduced into the calculations as pseudoobservations into the set of intermediate measurements $L$ and the weight matrix $P[7]$ :

$$
P=\left[\begin{array}{cc}
Q_{L}^{-1} & 0 \\
0 & Q_{X Y Z}^{-1}
\end{array}\right]
$$

This type of adjustment is advantageous in cases where the connection points are determined by GNSS. To a limited extent, the adjustment can be used to connect to geodetic bases. If the coordinate increments correspond to the a priori precision of the coordinates of the connection points they can be neglected. Otherwise, the connection point must be eliminated from the alignment or "fixed" in the adjustment calculation.

\section{Robust methods for finding remote observations in a survey net}

Robust statistical methods modify the classical methods of adjustment by LMS with statistical tests. They have a higher resistance to the degradation of results by remote observations. For practical application in geodetic tasks, M-estimates are the most suitable. They allow sufficient flexibility and can be computationally managed even in generalized linear model solutions.

The principle of the application of robust M-estimates is based on the iterative modification of LMS, which respects gradual changes in the weights of individual observations. The change of the robust measurement scale $w$ depends on the value of its correction $v$, i.e. on the estimate of the unknown $X$. The remote the observation, the lower its sturdy weight is and thus the lower its impact on the adjustment. In this way, outliers are gradually removed to give a robust estimate the independent effect of remote observations.

The robust measurement scales $w$ can be input to the weight matrix $W$ as

$$
W=\left[\begin{array}{cccc}
w_{1} & 0 & \cdots & 0 \\
0 & w_{2} & \cdots & 0 \\
\vdots & \vdots & \ddots & \vdots \\
0 & 0 & \cdots & w_{n}
\end{array}\right]
$$



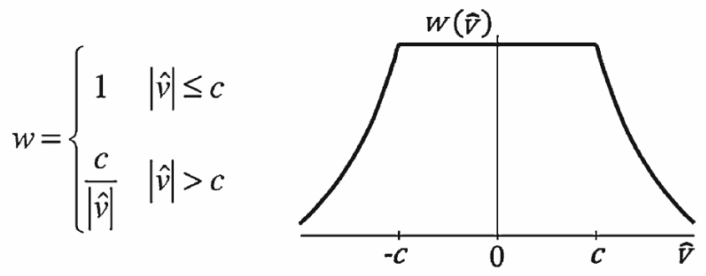

Figure 2: Huber's M-estimation - weight function [7, 21].

which can be input into the solution of a set of linearised equations $\hat{d x}$ in the general $j$-iterative step of LMS as

$$
\hat{d x}^{(j)}=-\left(A^{T} \cdot W^{(j)} \cdot P \cdot A\right)^{-1} \cdot A^{T} \cdot W^{(j)} \cdot P \cdot l^{\prime} .
$$

The application of robust estimates for the detection of outliers is a highly effective method bbut its usefulness is conditioned on many factors and input conditions. In order to achieve corresponding results, a sufficient number of redundant observations and a low incidence of remote observations in the measurement set $L$ must be ensured [7, 21].

\section{Case studies}

This section presents case studies in which the described computing methods were applied.

\subsection{Survey net: Kestrany}

In this case, the assignment was to design and a build the survey net which will serve as a spatial framework for detailed surveys. The subjects of detailed surveys were selected rooms in the historical building called the Upper Fortress in the village of Kestřany, Písek district, Czech Republic. Ground laser scanning was chosen as the main method of detailed surveys. The metric survey documentation of a part of the historical building was the assignment for two bachelor theses. $[18,4]$

It was surveyed both in the exterior and in the interiors, on the ground floor and in cellars. The detailed surveys were carried out together with the reconnaissance of the terrain and the construction of the survey net. The Leica TS02 FlexLine [9] was used to measure the net, the connection to S-JTSK and Bpv was made by RTK surveying on selected points of the survey net, i.e. 5001-5006. The Leica Viva GS15 GPS [9] was used for RTK surveying.

Digital field books, i.e. of the total station, were processed in the Kokeš software [6]. The processing and analyses of intermediate measurements were made using the custom production source code in the Matlab software [10]. The survey net was aligned in the Gama-local software [2]. The horizontal distances were corrected for the impact of Křovák's universal conformal conical projection and the impact of the altitude. For all calculations and accuracy testing, the $5 \%$ level of significance was used.

The global position precision corresponds to the LoD and LoA of the metric survey documentation in a reference map scale $1: 50$. 


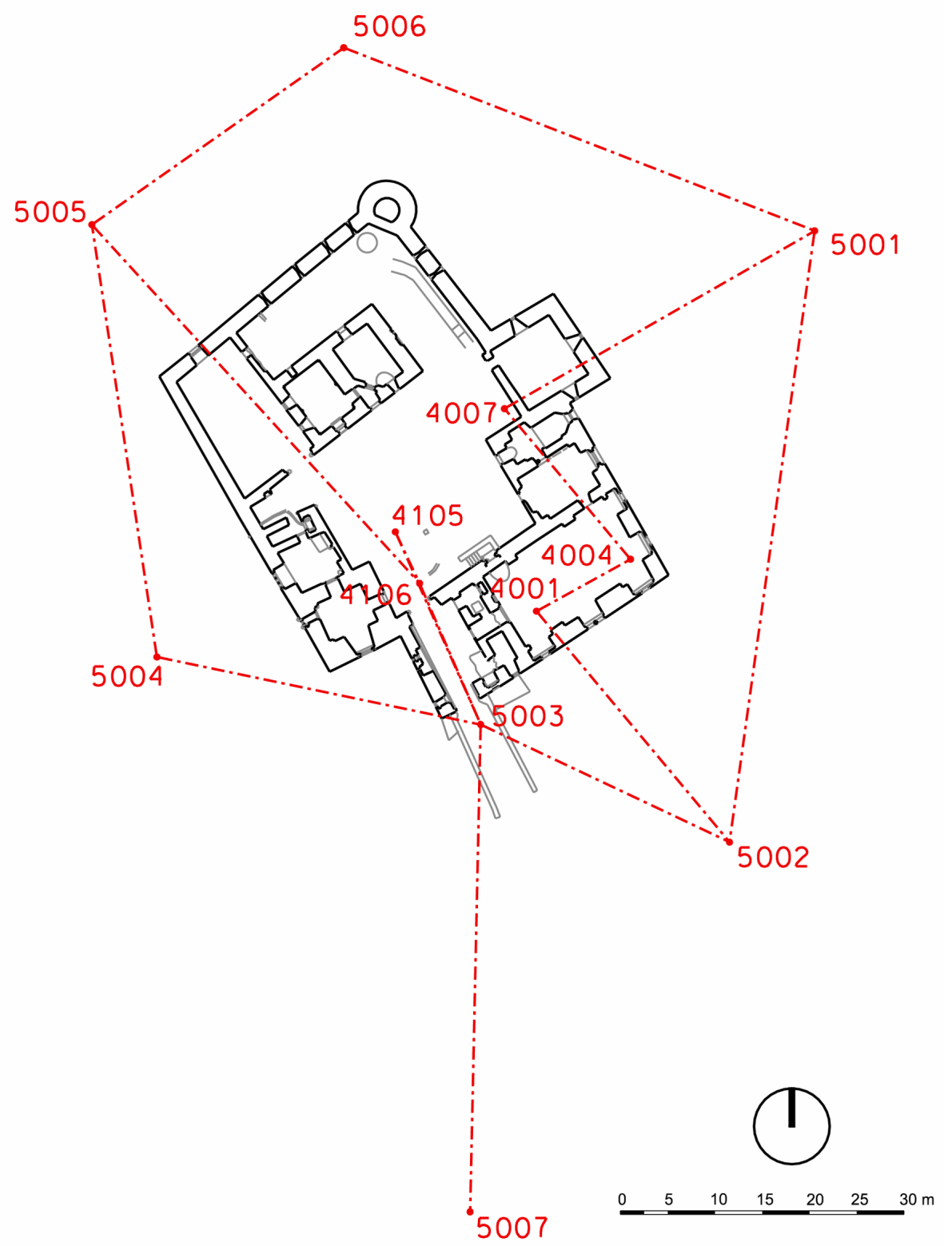

Figure 3: The scheme of the survey net in Kestřany.

\subsection{Survey net: Radkov}

The Radkov archaeological site is located in the Svitavy district, the Czech Republic. In this case, the assignment was to design and build a survey net which will serve as a single spatial framework for detailed mapping, geophysical surveys and digital terrain models (DTM) based on datasets from airborne laser scanning (ALS) [14].

Two-stage measurement was carried out. The first was done together with the reconnaissance of the terrain and the construction of the survey net. Leica TS06 FlexLine [9] was used and the Trimble R8s GNSS [22] provided the connection to S-JTSK and Bpv. The latter was 
Table 4: Basic parameters of the adjustment of the survey net in Kestřany.

\begin{tabular}{|c|c|c|c|}
\hline Type of coordinates & $\boldsymbol{X} \boldsymbol{Y} \boldsymbol{Z}$ & $\boldsymbol{X} \boldsymbol{Y}$ & $\boldsymbol{Z}$ \\
\hline Adjusted & 14 & 0 & 0 \\
\hline Constrained & 2 & 0 & 0 \\
\hline Fixed & 0 & 0 & 0 \\
\hline Summary & 14 & 0 & 0 \\
\hline \hline \multicolumn{4}{|c|}{ Set statistics } \\
\hline Directions & 29 & Sets of directions & 11 \\
\hline Distances & 20 & Residual equations & 74 \\
\hline Coordinates & 6 & Redundant observations & 21 \\
\hline Height differences & 19 & Unknowns & 53 \\
\hline Summary & 74 & Defects of survey net & 0 \\
\hline \hline \multicolumn{4}{|c|}{ Precision statistics } \\
\hline$m_{0}-$ a priory & 1 & $m_{0}^{\prime}-$ a posteriori & 0.94 \\
\cline { 2 - 4 } & 0.937 & 95\% interval & 18.45 \\
\hline$m_{0} / m_{0}^{\prime}$ & 8.5 & Average $\sigma_{\mathbf{X Y}}[\mathrm{mm}]$ & 5.0 \\
\hline Max. $\sigma_{\mathbf{X Y}}[\mathrm{mm}]$
\end{tabular}

focused only on the survey net. Leica NOVA TS50 was used for this measurement [9].

It was not possible to perform a net calculation from the datasets of the first measurement. That is why the coordinates were calculated by traverses without orientation and oriented distances. The horizontal distances were corrected for the impact of Křovák's universal conformal conical projection and the impact of the altitude. Coordinates are in S-JTSK and Bpv. The second measurement was aligned in the EasyNet software [1] as a geodetic micronetwork. For all calculations and accuracy testing, the $5 \%$ level of significance was used and Huber's method was chosen for robust analyses.

In the next step, the coordinates obtained from the network alignment were transformed to the coordinates calculated from the first alignment of the congruent transformation with the equalization of the transformation key. This calculation method preserved the internal precision of the survey net and docked it in S-JTSK.

The global position precision is determined as standard deviations to identify identical points by the RTK surveying, i.e. $\sigma_{X Y}=0.021 \mathrm{~m}$ and $\sigma_{Z}=0.05 \mathrm{~m}$. The global position precision corresponds to the LoD and LoA of the metric survey documentation in a reference map scale $1: 200$.

\subsection{Survey net: Holubice}

The Church of Nativity of Virgin Mary is located in the village of Holubice, Prague - West district, Czech Republic. In this case, the assignment was to design and build a survey net which served as a spatial framework for detailed surveys. The output was the basis for the Building Archaeological Survey [8] and the 3D model based on the photogrammetric processing of the image data [5] of the historical sacral building.

A two-step detailed survey was performed. The surveys were carried out together with the 


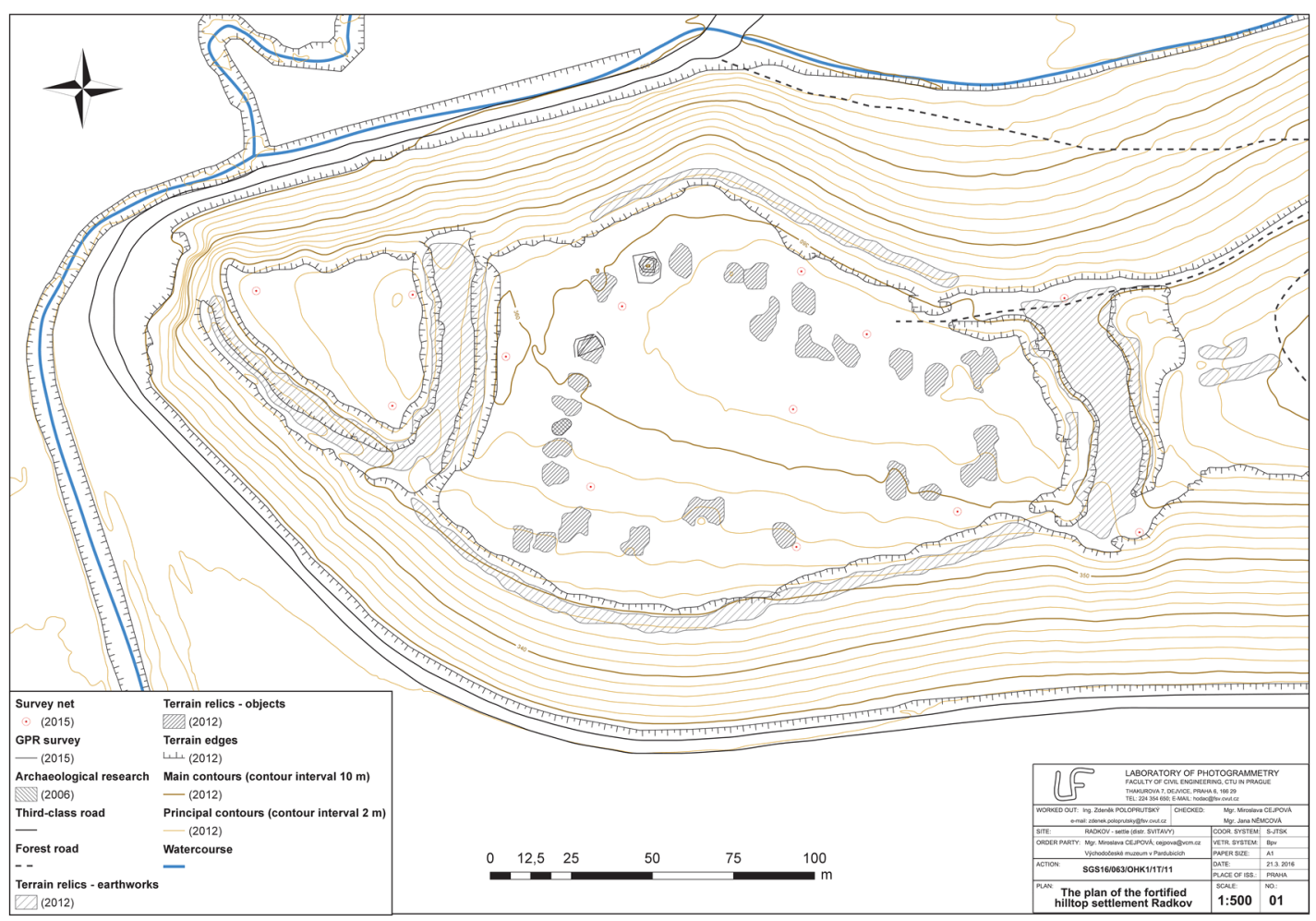

Figure 4: The plan of the fortified hilltop settlement Radkov [15].

reconnaissance of the terrain and the construction of the survey net. The first survey was performed by Leica TS02 FlexLine [9] and the second survey was performed by Leica TS06 FlexLine [9].

Since the stabilization marks of all the witness points of the trigonometric point forming the church tower were not found in the terrain, it was not possible to connect the network to S-JTSK. Therefore, it was aligned as a local network. The network was height-connected to Bpv.

Digital field books, i.e. of the total station, were processed in the Kokeš software [6]. The processing and analyses of intermediate measurements were made using the custom production source code in the Matlab software [10]. The survey net was aligned in the Gama-local software [2]. The horizontal distances were corrected for the impact of Křovák's universal conformal conical projection and the impact of the altitude. For all calculations and accuracy testing, the $5 \%$ level of significance was used.

The local position precision corresponds to the LoD and LoA of the metric survey documentation in a reference map scale $1: 20$.

\section{Conclusion}

This section summarizes and explains the principles which it is preferable to observe in the design of survey nets in historical buildings. 
Table 5: Basic parameters of the adjustment of the survey net in Radkov, internal precision.

\begin{tabular}{|c|c|c|c|}
\hline Type of coordinates & $X Y Z$ & $X Y$ & $Z$ \\
\hline Adjusted & 13 & 0 & 0 \\
\hline Constrained & 0 & 0 & 0 \\
\hline Fixed & 0 & 0 & 0 \\
\hline Summary & 13 & 0 & 0 \\
\hline \multicolumn{4}{|c|}{ Set statistics } \\
\hline Directions & 130 & Sets of directions & 14 \\
\hline Slope distances & 137 & Residual equations & 401 \\
\hline Zenithal distances & 134 & Redundant observations & 352 \\
\hline Height differences & 0 & Unknowns & 49 \\
\hline Summary & 401 & Defects of survey net & 4 \\
\hline \multicolumn{4}{|c|}{ Precision statistics } \\
\hline$m_{0}-$ a priory & 1 & \multirow{2}{*}{$m_{0}^{\prime}-$ a posteriori } & \multirow{2}{*}{0.704} \\
\hline$m_{0} / m_{0}^{\prime}$ & 0.704 & & \\
\hline Max. $\sigma_{\mathbf{X Y}}[\mathrm{mm}]$ & 0.56 & Average $\sigma_{\mathbf{X Y}}[\mathrm{mm}]$ & 0.33 \\
\hline
\end{tabular}

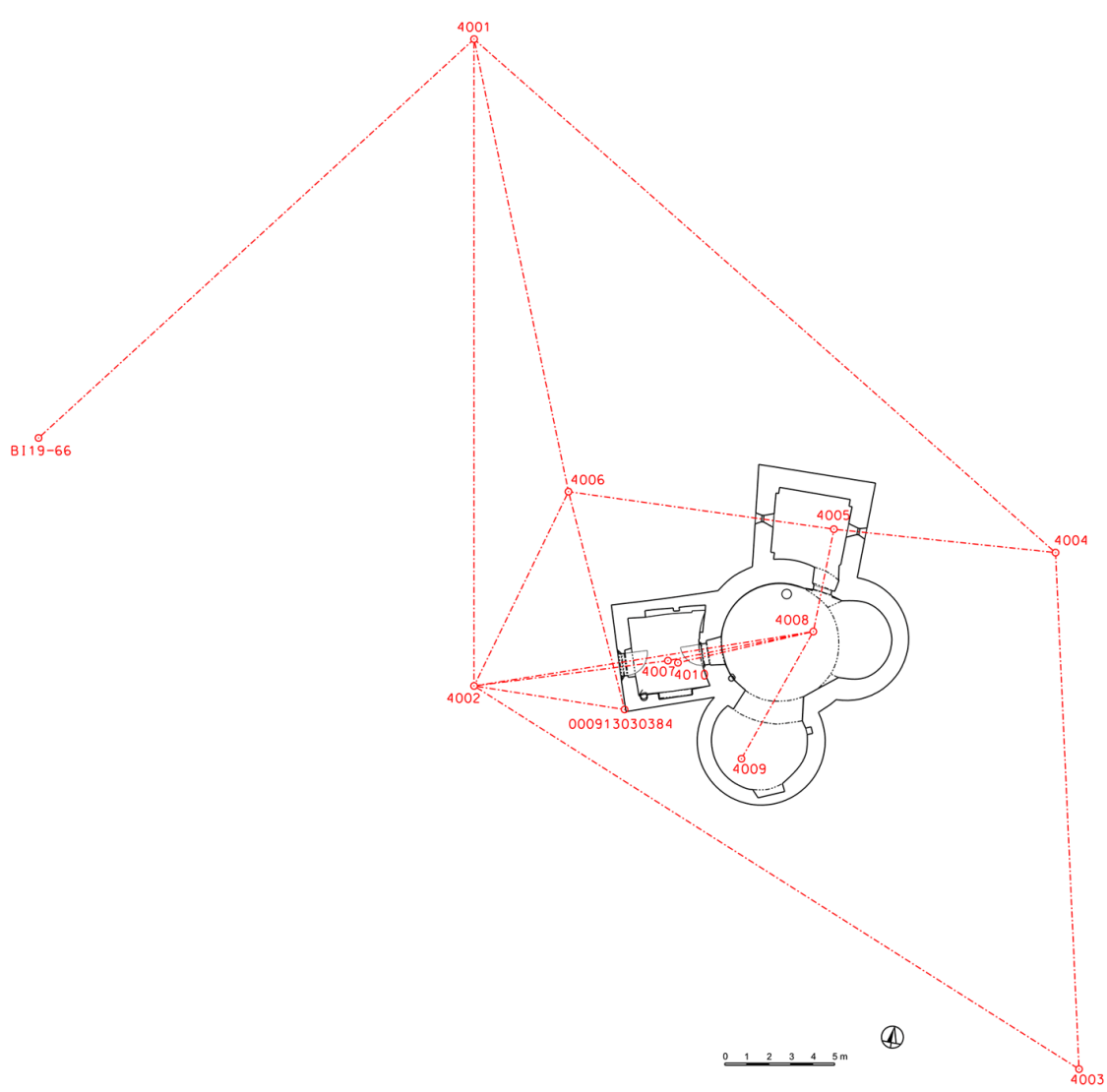

Figure 5: The scheme of the survey net in Holubice. 
Table 6: Basic parameters of the second phase of the adjustment of the survey net in Holubice.

\begin{tabular}{|c|c|c|c|}
\hline Type of coordinates & $\boldsymbol{X} \boldsymbol{Y} \boldsymbol{Z}$ & $\boldsymbol{X} \boldsymbol{Y}$ & $\boldsymbol{Z}$ \\
\hline Adjusted & 11 & 1 & 0 \\
\hline Constrained & 3 & 2 & 1 \\
\hline Fixed & 0 & 0 & 1 \\
\hline Summary & 11 & 1 & 6 \\
\hline \hline \multicolumn{4}{|c|}{ Set statistics } \\
\hline Directions & 17 & Sets of directions & 65 \\
\hline Distances & 14 & Residual equations & 24 \\
\hline Coordinates & 20 & Redundant observations & 41 \\
\hline Height differences & 14 & Unknowns & 0 \\
\hline Summary & 65 & Defects of survey net & 1.16 \\
\hline \hline \multicolumn{4}{|c|}{ Precision statistics } \\
\hline$m_{0}-$ a priory & 1 & $m_{0}^{\prime}-$ a posteriori & 32.33 \\
\cline { 2 - 4 } & 1.162 & 95\% interval & $(0.719 ; 1.281)$ \\
\hline$m_{0} / m_{0}^{\prime}$ & 2.4 & Average $\sigma_{\mathbf{X Y}}[\mathrm{mm}]$ & 1.7 \\
\hline Max. $\sigma_{\mathbf{X Y}}[\mathrm{mm}]$ & \multicolumn{3}{|c|}{} \\
\hline
\end{tabular}

\section{Survey net configuration towards the building}

Generally, the configuration of the survey net is advantageous when the surveyed object is disposed at the centroid of the survey net. The centroid of the survey net may not be stabilized in the field; it may be a mathematically determined point that serves as a reference point for which, for example, mathematical reductions can be applied to a geodetic reference system.

From the expected reference map scale of the metric survey documentation and LoD of the detailed survey, the basic dimensions of the survey net can be estimated, see Table 1 .

\section{Geometry of the survey net}

In this case, the geometry of the survey net means the deployment of survey points of the survey net in the vicinity and within the documented building. The displacement of survey stations in the survey net influences the shape of the net, its density and its side ratios. These parameters affect the calculation and accuracy of the survey net.

Each survey point should be chosen in order to achieve the maximum possible visibility to the surrounding survey points of the survey net to ensure redundant observations. This allows adjustment of the survey net by LSM.

\section{Layout and selection of the stabilization of survey points}

When stabilizing survey points in a building, it is preferable to proceed from "small to large" because the stabilization of the net provides more freedom to choose the optimal net geometry in the exterior than in the interior. The survey net should have a documented object located in its centroid in the exterior.

In the case of the stabilization of survey points in the interior, the survey point is ideally located in each room, because it is advantageous to know the altitude in each room for the 
purposes of the metric survey documentation of the historical building. If it is possible to view the door openings through multiple rooms, it is preferable to select the survey points so that they can be densified by means of temporary stations.

\section{Surveying equipment}

The basics of measuring equipment are the so-called set for the three-tripod system [20] and a tape measure, or a stake with stands, or a combination of both.

The interior may need additional lighting, for which it is necessary to ensure the luminaire, e.g. halogens, power supply and if necessary additional extension cables.

In the exterior, it may be advantageous to use the GNSS apparatus to connect the survey net to the reference systems. Additionally, it may be advantageous to use a levelling kit, i.e. a levelling instrument, a tripod, a levelling staff and a footplate, for levelling.

\section{Precision analyses, adjustment of a survey net and processing of observations}

In practice, measurements in historical buildings can be compared to measurements in underground spaces, i.e. the configuration of the survey net is so called "thin", which causes fewer redundant observations and unilaterally connecting survey points.

The effect of centering of an instrument and targets shows on the measuring accuracy if the survey net dimensions are in the order of tens to hundreds of meters.

Survey points in the interior must be connected through window and door openings with survey points in the exterior. This results in measurements under different lighting conditions that can affect the accuracy of targeting - refraction.

It is advantageous to process precision analyses before the survey and mathematical modelling of inputs - a combination of software for the adjustment of survey nets using LMS, basic geodetic calculations and base maps.

For precision analyses before the measurement and for the measurement itself, it is appropriate to follow several general principles:

- For a more accurate estimate of the accuracy of angular measurements, it is advisable to measure minimally in two groups.

- If possible, slope distances, zenithal distances and height differences should be measured against each other.

- Two planimetric survey points are required to connect to the positional coordinate reference system, more planimetric survey points are more appropriate.

- One height point is required to connect to the vertical coordinate reference system, more height points are more appropriate.

The method of adjustment of a survey net depends on the configuration and geometry of the survey net. The use of robust adjustment methods is worth in the case of an area survey net with a large number of redundant observations, i.e. $50 \%$ and above, see EasyNET software [1]. Robust adjustment methods may fail in the case of "sparse" survey nets with a small number of redundant observations, i.e. up to $50 \%$. Other software must be used, such as the Gama-local software [2]. 
The outcomes from detailed surveys must be processed according to the requirements defined in the specification. As a rule, they are further developed in specialized CAD, GIS software, etc.

\section{Acknowledgements}

This work was supported by the Grant Agency of the Czech Technical University in Prague, grant No. SGS17/068/OHK1/1T/11.

\section{References}

[1] Adjust Solutions. EasyNET. 2016. URL: http://adjustsolutions.cz/en/easynet/ (visited on 04/17/2017).

[2] Aleš Čepek. GNU Gama. Comp. software. GNU Operating System, 1998-2017. URL: https://www.gnu.org/software/gama/.

[3] ČÚZK. Geoportal ČÚZK: Access to map products and services. 2010. URL: http: // geoportal.cuzk.cz/ (visited on 04/12/2017).

[4] Kristýna Doležalová. Upper fortress Kestrany (Písek) - metrical documentation of selected part. Ed. by Jindřich Hodač. Barchelor thesis. Prague: Departments of Geomatics, FCE CTU in Prague, 2017.

[5] M. Faltýnová et al. "Complex Analysis and Documentation of Historical Buildings Using New Geomatic Methods". In: Stavební obzor - Civil Engineering Journal 25.4 (2016). ISSN: 18052576. DOI: 10.14311/CEJ .2016.04.0027.

[6] GEPRO. KOKE ̌. 2017. URL: http://www.gepro.cz/produkty/kokes/ (visited on 04/17/2017).

[7] Miroslav Hampacher and Martin Štroner. Zpracování a analýza měrení v inženýrské geodézii. Praha: Katedra speciální geodézie, České vysoké učení technické v Praze, 2011. ISBN: 978-80-01-04900-6.

[8] Milena Hauserová et al. "The church and its patrons: Two chapters from the history of building the rotunda of the Nativity of the Virgin Mary in Holubice". In: Déjiny staveb 2016. 17. mezinárodní konference DĚJINY STAVEB 2016. Vol. 17. Pilsen, Czech Republic: Klub Augusta Sedláčka, 2016, pp. 7-16. ISBN: 978-80-87170-48-9.

[9] Leica Geosystems. Leica Geosystems. 2017. URL: http://leica-geosystems.com/en/ (visited on 06/02/2017).

[10] MathWorks. MATLAB. 2017. URL: https://www . mathworks . com/products/matlab. html (visited on 04/17/2017).

[11] () OpenStreetMap contributors. OpenStreetMap. OpenStreetMap. 2017. URL: http : //www . openstreetmap.org/ (visited on 07/04/2017).

[12] Paper size. In: Wikipedia. Wikimedia Foundation, May 31, 2017. URL: https://en . wikipedia . org / w / index . php? title $=$ Paper _ size\& oldid $=783113730$ (visited on 06/03/2017).

[13] Jana Pařízková Čevonová et al. Building Archaeology Survey: A Methodology. Ed. by Jan Beránek and Petr Macek. 70. OCLC: 949216987. Prague: National Heritage Institute, 2015. ISBN: 978-80-7480-037-5. 
[14] Z. Poloprutský, M. Cejpová, and J. Němcová. "Non-Destructive Survey of Archaeological Sites Using Airborne Laser Scanning and Geophysical Applications". In: ISPRS International Archives of the Photogrammetry, Remote Sensing and Spatial Information Sciences XLI-B5 (June 15, 2016), pp. 371-376. ISSN: 2194-9034. DOI: 10.5194/isprsarchives-XLI-B5-371-2016.

[15] Zdeněk Poloprutský. The plan of the fortified hilltop settlement Radkov. Specialized map with expert content. Praque, 2016. URL: http://lfgm.fsv.cvut.cz/main.php? cap $=0 \& z a l=475 \& l$ ang $=$ en (visited on $03 / 23 / 2016$ ).

[16] Česká republika. 357/2013 Sb. - o katastru nemovitostí (katastrální vyhláška). Nov. 1, 2013. URL: https : / / portal · gov . cz / app / zakony / zakon · jsp ? page $=0$ \& $\mathrm{nr}=$ 357 2F2013\&rpp=15\#seznam (visited on 01/06/2016).

[17] Česká republika. 430/2006 Sb. - o stanovení geodetických referenčních systémů a státních mapových děl závazných na území státu a zásadách jejich použivání. Aug. 16, 2006. URL: http : / / portal . gov . cz / app / zakony / zakonPar . jsp ? idBiblio = 63017 \& fulltext $=\& \mathrm{nr}=430 \sim 2 \mathrm{~F} 2006 \&$ part $=$ \&name $=\& \mathrm{rpp}=15$ \# local - content (visited on $12 / 31 / 2015)$.

[18] Zuzana Richtrová. Upper fortress Kestřany (Písek) - metrical documentation of selected part. Ed. by Jindřich Hodač. Barchelor thesis. Prague: Departments of Geomatics, FCE CTU in Prague, 2016.

[19] (O) Seznam.cz. Mapy.cz. Mapy.cz. 2017. uRL: https://mapy.cz/ (visited on 07/04/2017).

[20] Terminological Commission of the Czech Office for Surveying Mapping and Cadastre. Terminological Dictionary VÚGTK. In: Terminological Dictionary of Geodesy, Cartography and Cadastre. Zdiby: VÚGTK, 2016. URL: http://www. vugtk.cz/slovnik/ index .php?jazykova_verze=cz (visited on 01/06/2016).

[21] Pavel Třasák and Martin Štroner. "Outlier detection efficiency in the high precision geodetic network adjustment". In: Acta Geodaetica et Geophysica 49.2 (2014), pp. 161175. ISSN: 2213-5812. DOI: $10.1007 /$ s40328-014-0045-9.

[22] Trimble. Trimble: Transforming the Way the World Works. 2017. URL: http://www. trimble.com/ (visited on 06/02/2017).

[23] Jan Veselý. Metric survey documentation of historic buildings for use in heritage management. 49. OCLC: 907529016. Prague: National Heritage Institute, 2014. ISBN: 97880-86516-79-0. 